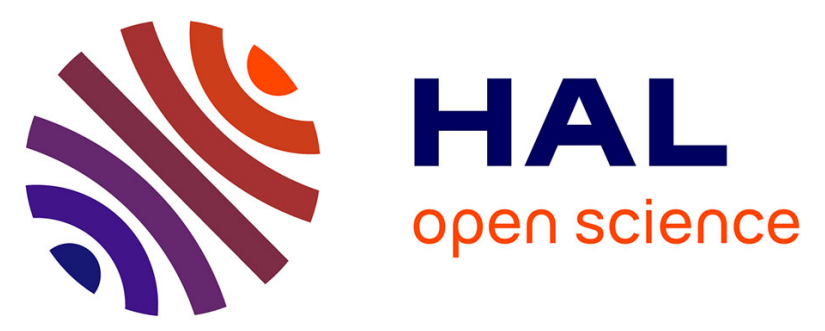

\title{
Geographic origin of migratory birds based on stable isotope analysis: the case of the greylag goose (Anser anser) wintering in Camargue, southern France
}

Matthieu Guillemain, Leo Bacon, Kevin J Kardynal, Anthony Olivier, Michal Podhrazsky, Petr Musil, Keith A Hobson

\section{To cite this version:}

Matthieu Guillemain, Leo Bacon, Kevin J Kardynal, Anthony Olivier, Michal Podhrazsky, et al.. Geographic origin of migratory birds based on stable isotope analysis: the case of the greylag goose (Anser anser) wintering in Camargue, southern France. European Journal of Wildlife Research, 2019, 65 (5), 10.1007/s10344-019-1304-4 . hal-02465223

\section{HAL Id: hal-02465223 \\ https://hal.science/hal-02465223}

Submitted on 3 Feb 2020

HAL is a multi-disciplinary open access archive for the deposit and dissemination of scientific research documents, whether they are published or not. The documents may come from teaching and research institutions in France or abroad, or from public or private research centers.
L'archive ouverte pluridisciplinaire HAL, est destinée au dépôt et à la diffusion de documents scientifiques de niveau recherche, publiés ou non, émanant des établissements d'enseignement et de recherche français ou étrangers, des laboratoires publics ou privés. 


\section{Geographic origin of migratory birds based on stable isotope analysis: the case of}

the greylag goose (Anser anser) wintering in Camargue, southern France

Matthieu Guillemain ${ }^{1} \&$ Leo Bacon ${ }^{1} \&$ Kevin J. Kardynal ${ }^{2} \&$ Anthony Olivier ${ }^{3}$ \& Michal Podhrazsky ${ }^{4,5} \&$ Petr Musil $^{6} \&$ Keith A. Hobson $^{2,7}$

1 Office National de la Chasse et de la Faune Sauvage, Unité Avifaune Migratrice, La Tour du Valat, Le Sambuc, 13200 Arles, France

2 Environment and Climate Change Canada, 11 Innovation Boulevard,Saskatoon, SK S7N 3H5, Canada

3 Institut de Recherche de la Tour du Valat, Le Sambuc,13200 Arles, France

4 ZOO Dvur Kralove, Stefanikova 1029, 54401 Dvur Kralove nad Labem, Czech Republic

5 Department of Zoology, Faculty of Natural Science, Charles University, Vinicna 7, 12844 Prague 2, Czech Republic

6 Department of Ecology, Faculty of Environmental Sciences, Czech University of Life Sciences, Kamýcká 1176, 16521 Prague 6, Czech Republic

7 Department of Biology, University of Western Ontario, Room 2025 BGS Building, 1151 Richmond St. N., London, Ontario N6A 5B7, Canada

* Matthieu Guillemain : matthieu.guillemain@oncfs.gouv.fr

How to cite : Guillemain M., Bacon L., Kardynal K.J., Olivier A., Podhrazsky M., Musil P., Hobson K.A. 2019. Geographic origin of migratory birds based on stable isotope analysis: the case of the greylag goose (Anser anser) wintering in Camargue, southern France. Eur J Wildl Res 65:67. doi: 10.1007/s10344-019-1304-4

\section{Abstract}

Proper delineation of flyways is a prerequisite for adequate management of migratory birds. The implementation of coordinated international management for greylag goose (Anser anser) is currently underway in Europe for the north-west/south-west (NW/ SW) population. Some uncertainty remained as to whether greylags wintering in Camargue, Southern France, belonged to this population and bred in Norway, Sweden and Finland,or rather originated from the Central European population, especially since most neck collar observations were of birds ringed in the Czech Republic. Stable hydrogen isotope $\left(\delta^{2} H\right)$ analyses of feathers from 147 individuals hunted or trapped during winter in Camargue provide some insight into this question and suggest northcentral Europe as a more likely area of origin. This indicates that greylags wintering along the Mediterranean coast maybe largely separate from the birds of the NW/SW European population breeding in Fennoscandia, although some individuals may also come from the Polish or German regions of the NW/SW flyway, since the combined ringing and stable isotope analyses suggest these birds are mostly breeding and moulting in an isotopic area consistent with the Czech Republic, Poland and northern Germany. Earlier studies show birds wintering in other French regions rather originate from Sweden and Norway. These results should be considered for the management plan currently being developed for greylag goose in Europe. More generally, they question whether birds from two distinct populations /flyways should be applied similar or potentially different management plans within a given country.

Keywords Anser anser, Greylag goose, Flyway delineation, International management plans, Deuterium, Stable isotopes

\section{Introduction}

Adequate management of migratory quarry species requires pre cise delineation of their flyways, in order to facilitate collaboration between countries at the appropriate geographic scale (Madsen et al. 2014). Indeed, distinct flyways of the same species may show very different trends in numbers of individuals or different migration strategies, requiring contrasting management approaches (e.g. see hunting regimes for the different Taïga Bean Goose Anser fabalis fabalis management units in Jensen et al. 2018).Arange of methods currently exist to delineate migratory bird flyways, all having their limitations un der various circumstances. For example, satellite tags are expensive to deploy on a sufficient number of birds, genetic analyses do not provide much information when even limited cross breeding occurs among populations (Kraus et al. 2013), feather isotopes alone may only provide coarse-scale information in some geographic regions (Guillemain et al. 2014) and ring re coveries may be biased when ringing effort or ring recovery probability (i.e. hunting pressure) vary over time and space (Korner-Nievergelt and Liechti 2012).

Management of goose species in Europe has advanced greatly over the last couple of years, with the gradual implementation of adaptive management schemes in order to regularly revise policy for these populations (potentially including their harvest) to 
current population size and knowledge about their dynamics (Madsen et al. 2017). As part of such a move, an international adaptive management plan has been adopted at the last meeting of AEWA parties for the north-west/south west (NW/SW) Europe population of greylag goose (Anser anser) (Powolny et al. 2018). Such a plan was required owing to the enormous growth of this population over the last de cades (8.5\%annualincreasebetween1980and2008; Foxand Madsen 2017) which, together with other European goose species, is causing conflict with agriculture and concern for disease transmission and air traffic safety in several countries (e.g. Bradbeer et al. 2017; Fox et al. 2017), although not in France so far (Powolny et al. 2018).

Some countries within the wintering range of greylag goose actually receive birds from both the NW/SW European and the Central European populations (Scott and Rose 1996). For in stance, birds wintering or migrating along the North Sea, Channel and Atlantic coast of France are considered to belong to the former flyway, with breeding grounds mostly in Sweden and Norway(Bacon e tal. 2019).Conversely, greylags observed on the French Mediterranean coast are believed to originate mostly from Central Europe (ONCFS 2014). This is by no means anecdotal since the Camargue is now the top winter quarter in the country with 2897 individuals recorded in mid January 2017, for a national total of 17,775 greylags (Gaudard et al. 2018), while very few greylags were wintering in this part of France before the 1990s (fewer than 50 geese during the 1980s on the main Camargue wintering site at Tour du Valat, Desnouhes et al. 2003). Ring recoveries and observations of neck collars in Camargue since 2005 support the assumption that despite changes in migratory behaviour following climate change (Fouquet et al. 2009; Podhrázský et al. 2017), birds present in the area mostly come from Central Europe (Fig. 1). Such data also suggest the Czech Republic is the main breeding area for birds wintering in Camargue; however, a particularly great effort has been deployed to ring and mark greylags with neck collars in that country (Podhrázský et al. 2017), which may provide a biased assessment of where most Camargue birds originate.

The aim of the present study was therefore to collect feathers of greylags wintering in Camargue and assess their geographic origin by means of stable isotope and probabilistic assignment analyses. The objectives of this study were to (i) determine if they were indeed mostly originating fromCentral Europe, and not Fennoscandia, and (ii) assess if such analyses would confirm the ringing data suggesting most Camargue greylags originate from the Czech Republic. Such information is crucial in determining the extent to which geese wintering along the Mediterranean coast of France should be considered in the new international management plan for the NW/SW European population, which mostly considers the birds breeding in Fennoscandia and western Europe. If not, the aim of this paper was also to assess which countries should be considered for establishing coordinated management within the Central European flyway or the eastern end of the NW/SW European flyway.

\section{Feather samples}

Feathers were collected from 147 different greylag geese captured, shot or found dead within the Rhône Delta (145,000ha) in Camargue, southern France (Supplementary Material 1) between the 2008-2009 and 2017-2018 hunting seasons. Of these, 119 were shot on the Tour du Valat estate $\left(43^{\circ} 30^{\prime}\right.$ N04 $40^{\prime}$ E) between 31 January 2009 and 30 January 2017. The Tour du Valat estate comprises not only a 1845-ha Nature Reserve but also 403 ha of hunted lands (ca. 50 ha of wetlands) where staff of the research station are allowed to hunt. Only one wing feather (remige) was collected per individual. Such feathers are grown only once per year in greylags and thus keep the isotope signature from the natal (in young birds) or moulting grounds (in adults). Information about sex and age of the individuals was generally not provided by the hunters and could hence not be considered in the analyses (see Supplementary Material 1).

\section{Laboratory methods}

Feather samples were transferred to $20-\mathrm{ml}$ glass scintillation vials and soaked in 2:1 chloroform:methanol solvent overnight. They were then decanted and rinsed and allowed to dry for $24 \mathrm{~h}$ in a fume hood. A subsample of $0.35 \mathrm{mg}$ of feather vane material was then weighed into silver capsules, crushed and loaded for stable isotope analysis.

Stable-hydrogen isotope analysis involved loading the unknowns and calibration standards in sequence on a Uni-Prep (Eurovector, Italy) carousel heated to $60{ }^{\circ} \mathrm{C}$ under vacuum. The carousel was flushed twice with dry helium, and then samples were combusted pyrolytically in a Eurovector 3000 elemental analyser using a ceramic reaction vessel with glassy carbon heated to $1350^{\circ} \mathrm{C}$. Resultant gases were separated by GC and the $\mathrm{H} 2$ gas introduced via an open split to a Thermo Delta V Plus isotope ratio mass spectrometer. Calibration correcting for $\mathrm{H}$ exchange was accomplished using two keratin standards (CBS - 197\%; KHS - 54\%) by means of the comparative equilibration technique (Wassenaar and Hobson 2003). Based on within-run ( $\mathrm{N}=6$ ) reproducibility of standards, we estimate measurement error to be $\pm 2 \%$. All stable isotope values are reported in delta notation relative to the Vienna Standard Mean Ocean Water (VSMOW) scale. 


\section{Summary statistics and assignment method}

Descriptive statistics to compare monthly and annual isotope values were conducted using analysis of variance (ANOVA) using the Statistica 10 software (Statsoft 2011). A spatially explicit likelihood assignment approach (Royle and Rubenstein 2004; Hobsonetal. 2009; Hobson 2018) was then used to assign the population to potential areas of origin. To accomplish this,the amount-weighted growing-season precipitation surface from Bowen et al. (2005; $\delta^{2} \mathrm{H}$ p) was converted to a feather isoscape using the calibration equation for European Mallards (Anas platyrhynchos) from van Dijk et al. $\left(2014 ; \delta^{2} H_{f}=-27.4+1.28 \times \delta^{2} H\right.$ $\delta^{2} \mathrm{H}$ p). These calibration algorithms were developed based on the keratin standard $\delta^{2} \mathrm{H}$ values (CBS and KHS) used in this study. A similar calibration is not specifically available for geese, and this species provides the only published equation for European waterfowl. That study did not publish an explicit value for the standard deviation of the residuals of their linear regression model and so the standard deviation from Lesser Scaup (Aythya affinis) $\delta^{2} \mathrm{H}_{\mathrm{f}}$ regressed against the same isoscape (SD $=12.6 \%$; Hobson et al. 2009) was used and incorporated into the as signments as an estimate of error. To determine the sensitivity of the probabilistic assignments to increases in the standard deviation, assignments were also conducted using a standard deviation of 25 , which is greater than most of the published values (Hobson and Wassenaar 2018). The resulting calibrated feather isoscape was then clipped to a potential greylag goose natal and moulting range map based on BirdLife International and NatureServe (2011) range maps modified using published data (Scott and Rose 1996).

We then applied a normalized probability density function (Hobsonetal. 2009)to estimate the probability that individual cells in the calibrated feather isoscape represented a potential origin for each bird. Individual birds were assigned to potential natal and moulting origins based on a Bayesian framework incorporating a spatially explicit isotope-based likelihood function applied at each pixel. We then applied a 2:1 odds criterion for accepting any given pixel as a potential origin and assigned pixels as either 1 or 0 , accordingly. Assignment results for individual birds were subsequently 'stacked' for the sample to depict potential breeding origin for the population. Digital file manipulation and assignment to origin analyses were conducted using multiple packages including 'raster' v.2.3 (Hijmans 2015) and 'maptools' v0.8 (Bivand and Lewin-Koh 2015) in the R statistical computing environment v3.2.2 (R Core Development Team 2015).

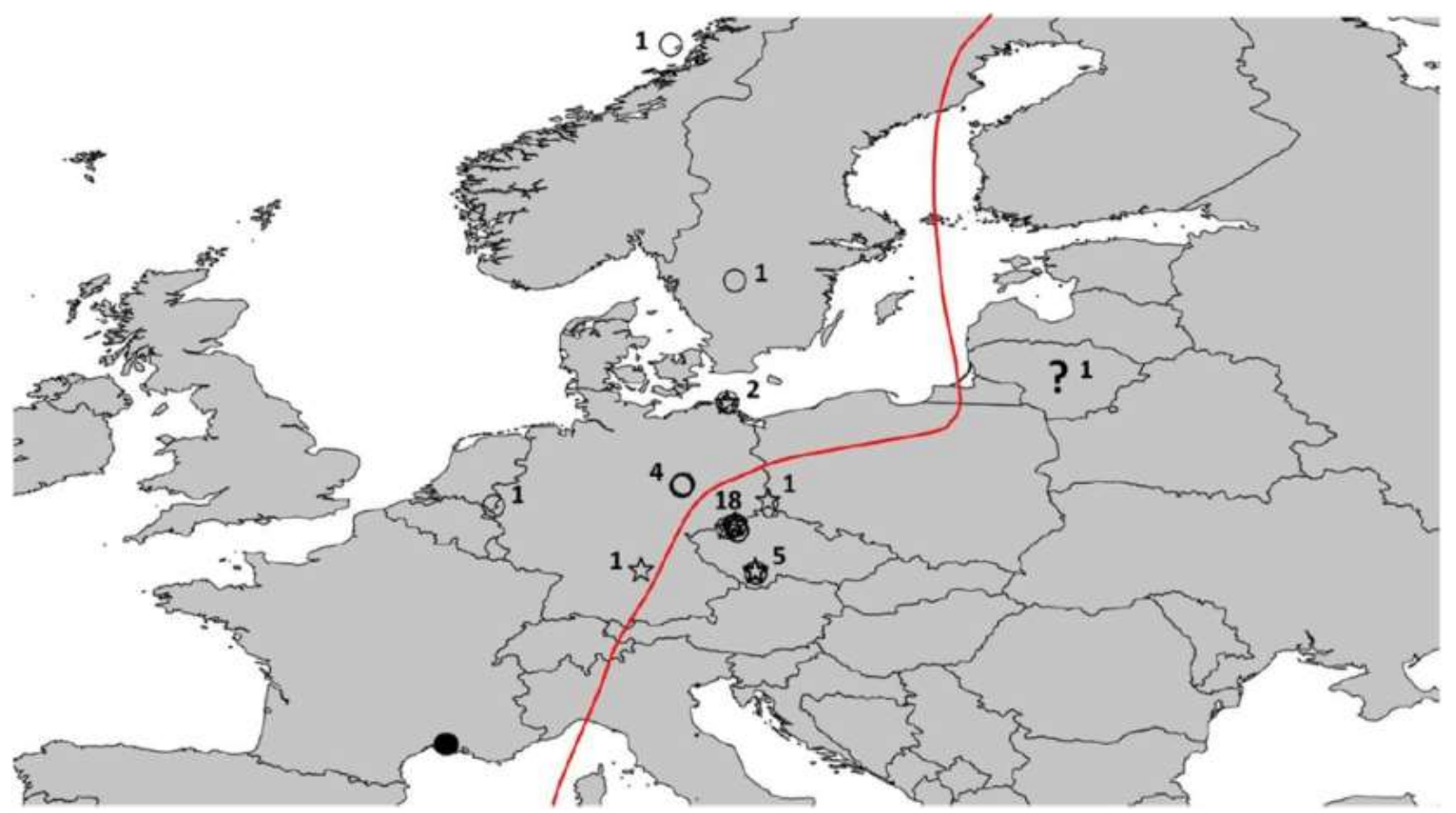

Fig. 1 Geographic origin of the 34 greylag geese observed or recovered in Camargue (black dot) since 2005. Stars represent the ringing sites of birds later recovered (i.e.hunted) in the Camargue, while circles show the origin of birds observed alive through their neck-collar. Some signs actually illustrate neighbouring ringing locations of more than one bird: numbers beside the signs indicate the number of different individuals (source of the data: www.geese.org and Dehorter \& CRBPO 2018). One ring from Lithuania is indicated on the map with a question mark because the exact place of ringing could never be ascertained owing to the death of the ringer. The red curve indicates the assumed boundary between the NW/SW European and the Central European greylag goose flyways after Scott \& Rose (1996) 


\section{Results}

Stable $\mathrm{H}$ isotope values among the 147 greylag goose feathers were consistent, with 110 birds (75\%) lying between - 120 and $90 \%$ values (Fig. 2). Mean isotope values were similar between feathers collected in November, December or January (F2,126 $=0.04, \mathrm{P}=0.96$; Fig. 2), the seven birds with a known collection date during any of the other months were discarded from the analyses. Similarly, the mean isotope value was similar among the years of collection, those with a known collection date before the 2010-2011 hunting season ( $n=7$ birds) being excluded from the analysis ( $F 6,129=0.29, P=0.94 ;$ Fig. 3). In general, these discarded individuals had isotope values within the main range of the other birds, but there were also considerable outliers (e.g. bird no. 95 or 115 in the Electronic Supplementary Material), which could also indicate different origins and could have included some locally born birds.

Based on feather isotopes from each individual, the results of the probabilistic assignment exercise for the breeding/ moulting origin of greylag geese wintering in Camargue are shown in Fig. 4. This depiction illustrates that the isotope values in wing feathers were consistent with a geographic origin across a band of latitude extending from the UK across north-central Europe, particularly consistent with Poland and north-eastern Germany. The assignment to origin analysis using a higher standard deviation showed very similar regions of origin (not shown), indicating that the analysis was robust to an increased standard deviation.

\section{Discussion}

Feather $\delta^{2} \mathrm{H}$ values from our sample are consistent with a geographic origin either in the UK or in north-central Europe, reflecting the nature of the underlying feather isoscape and the ambiguity often associated with bands of latitude. Greylags breeding in the UK are, however, mostly resident feral birds, and the UK is not known as a major moulting area for greylags breeding elsewhere (Mitchell and Fox 1999). It is therefore reasonable to conclude that the feathers of greylag geese wintering in Camargue mostly originate from northern central Europe. Although a Danish or even Dutch origin cannot be completely ruled out (see the few blue dots on map in Fig. 4), the core of the region of origin after the isotope analyses lies in Poland and northeastern Germany.



Fig. 2 Number of Camargue greylag goose feathers per category of $\delta^{2} \mathrm{H}$ isotope values(expressed in per mil). -120 stands for the interval from -120 to -110.1 


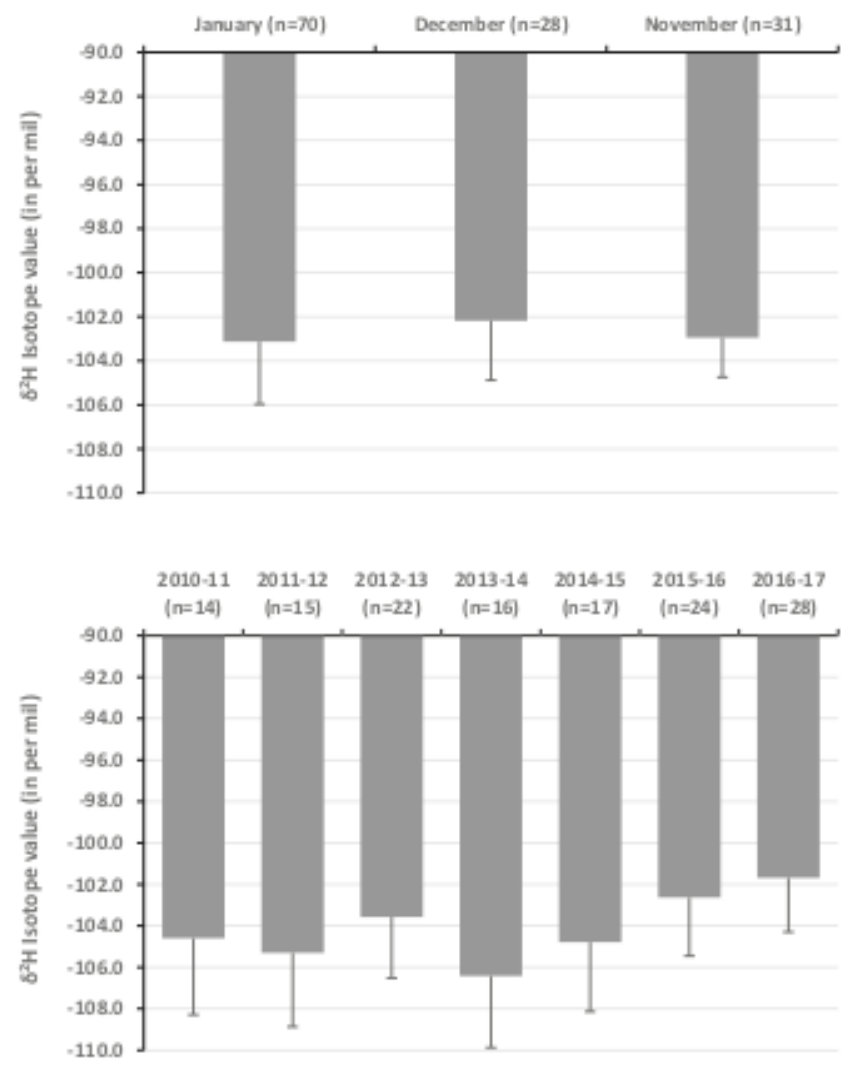

Fig. 3 Mean Camargue greylag goose feather $\delta^{2} \mathrm{H}$ isotope values expressed in per mil per month (top) and hunting season (bottom). Vertical bars show standard errors. No significant difference was found between months or between hunting seasons (see text) 




Fig. 4 Depiction of the origins of the sample of Camargue greylag goose feathers, based on stable isotope analyses. The bluer the area, the higher the number of birds that potentially originated from that area. See 'Methods' for an explanation of the procedure used. The red curve indicates the assumed boundary between the NW/SW European and the Central European greylag goose flyways after Scott \& Rose (1996). The red star shows the Camargue

The $\delta^{2} \mathrm{H}_{\mathrm{f}}$ values were consistent across years and among months of feather collection, indicating the Camargue greylag geese likely originated from the same general breeding/ moulting areas. A parsimonious consideration of the range in error in $\delta^{2} \mathrm{H} f$ to be expected from any given location is of the order of $12 \%$ which was propagated in our Bayesian based assignment, incorporating that error still distinguished areas north of the Czech Republic, Poland and northern Germany as being likely origins. Other sources of error involve potential year-to-year variation in the IAEA-GNIPbased precipitation $\delta^{2} \mathrm{H}$ data for Europe, but the long-term database appears consistent with little advantage to considering year-specific variation (Vander Zanden et al. 2015). Based on a long-term $\delta^{2} H$ and $\delta^{18} \mathrm{O}$ analysis of river waters in Germany, Reckerth et al. (2017) found that rivers can serve as a proxy for long-term average precipitation. Those authors demonstrated long-term stability in the northern German river water isotopic dataset (2002-2013) and, by extension, the

GNIP data record for this region. Thus, it is unlikely that the years corresponding to moult in our greylag feather sample were not in any way anomalous compared to the expected growing season precipitation used in our model. Although other stable isotopes $\left(\right.$ e.g. $\left.{ }^{13} \mathrm{C}, \delta^{15} \mathrm{~N}\right)$ can be useful in increasing the precision of probabilistic assignments (Hobson and Wassenaar 2018), there is little spatial variation in $\delta^{13} \mathrm{C}$ across Europe and there are issues with anthropogenic inputs altering local $\delta^{15} \mathrm{~N}$ values, which potentially skews results.

Our isotope results do not preclude the Czech Republic but rate that area as generally of lower probability of origin given our odds ratio. It should also be noted that the nature of the largely east-west isoclines in predicted feather $\delta^{2} \mathrm{H}$ values means that we cannot easily distinguish between northern Germany and Poland using isotope data alone. Another source of error in our assignments was the use of an assumed calibration relationship derived from mallards in Europe. While this calibration was the 
most appropriate available, we encourage further refinement of calibrations between goose feathers grown and known sites and the long-term GNIP data at those sites (Hobson 2018).

It is surprising that the isotope results point to Poland and NE Germany as the main regions of origin for the greylags wintering in Camargue, while most ring recoveries and observations of neck collars rather suggest a Czech origin (it should be noted, though, that 2 Polish collared greylags were observed very recently in the Tour du Valat, after the present analyses were run). However, rings are often fitted to birds on the hatching area and/or the breeding grounds, when the young are still flightless, while the isotopes are related to where the feathers were grown (in juveniles, that is, on the natal sites) or moulted (in adult birds). It is therefore possible that some of the birds observed in Camargue during winter actually bred in the Czech Republic but then moulted in Poland or NE Germany during later years or post-breeding for adults; hence, the ring/collar and the isotope data would not be contradictory to each other. There are no records of individual geese caught on a Czech breeding site and record ed moulting in another country during the same year. However, the Czech ringing database contains records of

28 individuals collared in the Czech Republic as yearlings and 7 individuals marked as older birds (> 1 year old), which were observed moulting in Germany or Poland during subsequent years (M. Podhrázský, unpub. data). Recoveries of Czech greylag goose rings are also common in Poland and especially Germany, demonstrating frequent movements of individuals between these countries (Hudec 2008; Podhrázský et al. 2017).

A non-mutually exclusive hypothesis is that some of the Camargue birds were not only moulting in Poland and NE Germany but actually also originating from these countries as their breeding grounds as well. Both countries do host major breeding sites for greylag geese (Nilsson et al. 1999; Dick et al. 1999). It is possible that a disproportionate ringing effort in the Czech Republic compared to, for instance, Poland, simply led to the over-representation of Czech birds among the rings recovered or the neck collars observed during winter in Camargue. The total number of greylags fitted with a neck collar between 2000 and 2017 was 702 and 601 in the Czech Republic and Poland, respectively, while the numbers of birds ringed in the two countries were 1076 and 849 (Podhrázský and Mokwa, unpub. data). Such very similar figures in the Czech Republic and Poland allow ruling out the hypothesis of disproportionate marking effort leading to a biased evaluation of the geographic origin of greylags wintering in the Camargue. It is therefore reasonable to say that the ringing and isotope data, given their associated margins of error, collectively point to central Europe (Czech Republic, Poland and Eastern Germany) as the most likely region of origin for the birds wintering along the Mediterranean coast of France. One future improvement of this research program will be to train the local hunters to determine the age of the shot birds, which will help separate feathers from breeding (juvenile birds) and moulting sites (adult birds) in the sample. Interestingly, no link could be demonstrated between the birds shot during winter on the Tour du Valat estate and the very small local breedingpopulationinMaraisduVigueirat,10km to the east (which hosts ca. 25 pairs; Massez 2009). Fitting satellite tags to the wintering greylags to better understand their movements and place of origin is also an obvious research need for the near future.

Some earlier studies have considered the Camargue greylag geese to belong to the NW/SW European flyway and the boundary between this and the Central European flyway to lie somewhere within Poland and the Czech Republic (Scott and Rose 1996; Dick et al. 1999; Podhrázský et al. 2017). The present isotope results, although they do not allow completely ruling out a geographic origin in Denmark or NW Germany, do point to NE Germany and Poland as a more likely region of origin for the birds wintering in Camargue (Fig. 4). It is a fact that the currently accepted boundary between the NW/SW European flyway and theCentral European flyway runs across northern Poland and the core region of origin suggested by the isotope analyses. However, recent kernel analyses of neck collar data at the European scale actually found very few of the NW/SW European breeding greylags to wander into these countries (Bacon et al. 2019), so that Poland and the Czech Republic are not considered in the International Single Species Management Plan for the NW/SW European population (Powolny et al. 2018). It could be that future research (e.g. based on satellite tag or new analyses of ringing data) leads to a redefinition of the exact flyway boundaries, as done recently for Common Teal Anas crecca, for example (Guillemain et al. 2017). In any case, the present results suggest the Camargue wintering greylags do not originate from Norwegian or Swedish breeding grounds in the NW/SW flyway as do the birds wintering in north-east France or along the Atlantic Coast but come from northern Central Europe with a much greater likelihood. This outcome appears essential to discern management interests at the regional scale. Indeed, it is envisioned that an adaptive management scheme will be set up for greylags in NW Europe (Madsen et al. 2017), which may lead to a change in hunting legislation in some countries of the wintering range such as Spain and France. While this would be highly relevant for geese wintering on the French North Sea, Channel and Atlantic coasts, the present results suggest it would be irrelevant to include the birds wintering in the Camargue. These should rather be included in a separate management plan for the birds originating from Central Europe, which remains to be written. Such results also question the extent to which birds from 
the same species but originating from different flyways/populations shall be applied similar management procedures within a given country.

Acknowledgements We would first like to thank the Camargue hunters, especially those from the Tour du Valat hunting group, for providing the greylag feathers. We also thank the Camargue ornithologists who have provided their resightings of neckcollared birds, as well as the Centre de Recherches sur la Biologie des Populations d'Oiseaux, Muséum National d'Histoire Naturelle, especially Olivier Dehorter and all the ringers in Central Europe who contributed to this dataset, forthering recovery data. The neck collar observation data for the Camargue were kindly provided by Lisenka de Vries for www.geese.org. We also greatly appreciated the valuable information provided by Ingolf Todte, Tomasz Mokwa and Łukasz Ławicki. Tony Fox, Richard Inger, Ruedi Nager, Christian Gortázar and an anonymous referee provided valuable comments on an earlier version of the manuscript

\section{References}

Bacon L, Madsen J, Jensen GH, de VL, Follestad A, Koffijberg K, Kruckenberg H, Loonen M, Månsson J, Nilsson L, Voslamber B, Guillemain M (2019) Spatio-temporal distribution of greylag goose Anser anser resightings on the north-west/south-west European fly- way: guidance for the delineation of transboundary management units. Wildl Biol 2019. https://doi.org/10.2981/wlb.00533

BirdLifelnternational,NatureServe(2011)Birdspeciesdistributionmaps of the world Birdlife International and Nature Serve, Cambridge and Arlington

BivandRS,Lewin-KohN(2015)MaptoolsVersion0.8-37. http://CRAN.R-project.org/package=maptools

Bowen GJ, Wassenaar LI, Hobson KA (2005) Global application of stable hydrogen and oxygen isotopes to wildlife forensics. Oecologia143:337-348

Bradbeer DR, Rosenquist C, Christensen TK, Fox AD (2017) Crowded skies: conflicts between expanding goose populations and aviation safety. Ambio 46(Suppl.2):S290-S300

Dehorter O, CRBPO (2018) Base de données de baguage et de déplacements d'oiseaux de France/Bird ringing and movement da-tabase for France. Centre de Recherches sur la Biologie des Populations d'Oiseaux, Muséum National d'Histoire Naturelle, Paris. http://crbpo.mnhn.fr/. Exctracted on 14th February 2018

Desnouhes L, Pichaud M, Le Clainche N, Mesléard F, Giroux JF (2003) Activity budget of an increasing wintering population of greylag geese Anser anser in southern France. Wildfowl 54:41-51

Dick G,Baccetti N, Boukhalfa D,Darolova A, Faragó S,Hudek K, Leito A, Markkola J, Witkowski J (1999) Greylag goose Anser anser: Central Europe/North Africa. In: Madsen J, Cracknell G, Fox T (eds) Goose populations of the western Palearctic. Wetlands International publication no. 48. National Environmental Research Institute, Rönde, pp 202-213

Fouquet M, Schricke V, Fouque C (2009) Greylag geese Anser anser depart earlier in spring: ananalysisof goose migrationfromwestern France over the years 1980-2005. Wildfowl 59:143-151

Fox AD, Madsen J (2017) Threatened species to super-abundance: the unexpected international implications of successful goose conserva- tion. Ambio 46(Suppl.2):S179-S187

Fox AD, Elmberg J, Tombre IM, Hessel R (2017) Agriculture and her- bivorous waterfowl: a review of the scientific basis for improved management. Biol Rev 92:854-877

Gaudard C, Quaintenne G, Ward A, Dronneau C, Dalloyau S (2018) Synthèse des dénombrements d'Anatidés, de foulques et de limicoles hivernant en France à la mi-janvier 2017. Ligue pour la Protection des Oiseaux, Rochefort

Guillemain M, Van Wilgenburg SL, Legagneux P, Hobson KA (2014) Assessing geographic origins of teal (Anas crecca) through stable- hydrogen $\left(\delta^{2} H\right)$ isotope analyses of feathers and ring-recoveries. J Ornithol 155:165-172

Guillemain M, Calenge C, Champagnon J, Hearn R (2017) Determining the boundaries of migratory bird flyways: a Bayesian model for Eurasian teal Anas crecca in western Europe. J Avian Biol 48: 1331-1341 
Hijmans RJ (2015) Raster version 2.3-24. Accessible at http://CRAN.R-project.org/package=raster

Hobson KA (2018) Application of isotopic methods for tracking animal movements. In: Hobson KA, Wassenaar LI (eds) Tracking animal migration with stable isotopes, Second edn. Academic Press, London, pp 85-116

Hobson KA, Wassenaar LI (eds) (2018) Tracking animal migration with stable isotopes, Second edn. Academic Press, London Hobson KA, Wunder MB, Van Wilgenburg SL, Clark RG, Wassenaar LI (2009) A method for investigating population declines of migratory birdsusingstableisotopes:originsofharvestedlesserscaupinNorth America. PLoS One 4:e7915.

https://doi.org/10.1371/journal.pone. 0007915

Hudec K (2008) Husa velká Anser anser. In: Cepák J, Klvaňa P, Formánek J, Horák D, Jelínek M, Schröpfer L, Škopek J, Zárybnický J (eds) Altas migrace ptáků. České a Slovenské republiky. Czech and Slovak bird migration atlas. Aventinum, Prague, pp 112-115

Jensen GH, Fox AD, Christensen TK, Clausen P, Koffijberg K, Liljebäck N, Mitchell C, Nilsson L, Alhainen M (2018) Taiga bean goose population status report 2017-2018. Report from the AEWA European Goose Management Platform Data Centre. Available from http://www.unep-aewa.org/sites/default/files/document/ AEWA_EGMIWG_3_11_TBG_pop_report.pdf

Korner-Nievergelt F, Liechti FHS (2012) Migratory connectivity derived from sparse ring reencounter data with unknown numbers of ringed birds. J Ornithol 153:771-782

KrausRHS, vanHooftP, MegensH-J,TsveyA, FokinSY,YdenbergRC, Prins HT (2013) Global lack of flyway structure in a cosmopolitan bird revealed by a genome wide survey of single nucleotide poly- morphisms. Mol Ecol 22:41-55

Madsen J, Tjørnløv RS, Frederiksen M, Mitchell C, Sigfússon AT (2014) Connectivity between flyway populations of waterbirds: assessment of rates of exchange, their causes and consequences. J Appl Ecol 51: 183-193

Madsen J, Williams JH, Johnson FA, Tombre IM, Dereliev S, Kuijken E (2017) Implementation of the first adaptive management plan for a European migratory waterbird population: the case of the Svalbard pink-footed goose Anser brachyrhynchus. Ambio 46(Suppl.2): S275-S289

Massez G (2009) Oie cendrée Anser anser. In: Flitti A, Kabouche B, Kayser Y, Olioso G (eds) Atlas des oiseaux nicheurs de Provence- Alpes-Cote d'Azur. Delachaux et Niestlé, Paris, pp 40-41

Mitchell C, Fox AD (1999) Feral greylag geese Anser anser: United Kingdom. In: Madsen J, Cracknell G, Fox T (eds) Goose populations of the western Palearctic. Wetlands International Publication No. 48. National Environmental Research Institute, Rönde, pp 178-180

Nilsson L, Follestad A, Koffijberg K, Kuijken E, Madsen J, Mooij J, Mouronval JB, Persson H, Schricke V, Voslamber B (1999) Greylag goose Anser anser: Northwest Europe. In: Madsen J, Cracknell G, Fox T (eds) Goose populations of the western Palearctic. Wetlands International Publication No. 48. National Environmental Research Institute, Rönde, pp 182-201

Office National delaChasse et de laFaune Sauvage (2014) Amélioration des connaissances sur l’oie cendrée en France. Rapport final. ONCFS, Paris

PodhrázskýM,MusilP,MusilováZ,ZouharJ,AdamM,ZávoraJ,Hudec K (2017) Central European greylag geese Anser anser show a shortening of migration distance and earlier spring arrival over 60 years. Ibis 159:352-365

Powolny T, Jensen GH, Nagy S, Czajkowski A, Fox AD, Lewis M, Madsen J (Compilers) (2018) AEWA international single species management plan for the greylag goose (Anser anser) - northwest/ southwest European population. AEWATechnical Series, Bonn

R Core Development Team (2015) R: a language and environment for statistical computing. R Foundation for statistical computing, Vienna

Reckerth A, StichlerW, Schmidt A, StumppC (2017) Long-term dataset analysis of isotopes in German rivers. J Hydrol 552:718731 
Royle JA, Rubenstein DR (2004) The role of species abundance in de- termining breeding origins of migratory birds with stable isotopes. Ecol Appl 14:1780-1788

Scott DA, Rose PM (1996) Atlas of Anatidae populations in Africa and Western Eurasia. Wetlands International, Wageningen

StatSoft (2011) STATISTICA, version 10. www.statsoft.fr

Van der Zanden HB, Wunder MB, Hobson KA, Van Wilgenburg SL, Wassenaar LI, Welker JM, Bowen GJ (2015) Space-time tradeoffs in the development of precipitation isotope models for determining migratory origin. J Avian Biol 46:658-667

Van Dijk JGB, Meissner W, Klaassen M (2014) Improving provenance studies in migratory birds when using feather hydrogen stable iso- topes. J Avian Biol 45:103-108

Wassenaar LI, Hobson KA (2003) Comparative equilibration and online technique for determination of non-exchangeable hydrogen of keratins for use in animal migration studies. Isot Environ Healt S 39:1-7 